ISSN: $1130-3743$

\title{
LA CARTA DE LA TIERRA: EXPERIENCIAS INTERNACIONALES DE INNOVACIÓN EN EDUCACIÓN SUPERIOR
}

\author{
The Earth Charter: international experiences of innovation \\ in Higher Education
}

\section{La Charte de la Terre: expériences internationales de l'innovation dans l'enseignement superieur}

\author{
María ARenas Ortiz*, Eva Francisca Hinojosa PAREjA** y María Carmen López López** \\ * Universidad de Granada. Facultad de Ciencias de la Educación. Departamento \\ de Pedagogía. Campus Universitario de Cartuja. 18071 Granada. \\ Correo-e: marenas@ugr.es \\ ** Universidad de Granada. Facultad de Ciencias de la Educación. Departamento \\ de Didáctica y Organización Escolar. Campus Universitario de Cartuja. 18071 \\ Granada.Correo-e: ebinojosa@ugr.es; mclopez@ugr.es
}

Fecha de recepción: enero de 2013

Fecha de aceptación definitiva: abril de 2013

Biblid [(1130-3743) 25, 1-2013, 79-107]

RESUMEN

La Carta de la Tierra es una iniciativa de la sociedad civil que pretende reforzar el valor de la sostenibilidad y la interdependencia entre las personas y sus contextos (Gorvachev, 2006). Esta declaración, avalada por la UNESCO, es considerada un instrumento de gran valor educativo en proyectos internacionales como el Decenio de la Educación para el Desarrollo Sostenible (2005-2014) promovido por Naciones Unidas. Este trabajo se centra en el estudio, a través de una metodología basada en 
el análisis de contenido, de distintas experiencias internacionales que toman la Carta de la Tierra como referente de innovación en la Educación Superior.

Los resultados obtenidos nos aproximan a las acciones emprendidas, a la naturaleza de las motivaciones que las hace posibles, los avances experimentados, el grado de compromiso adquirido por los agentes y comunidades implicadas, al tiempo que proporcionan claves para avanzar en el desarrollo de nuevas iniciativas en Educación Superior más comprometidas con la sostenibilidad.

Palabras clave: educación sostenible, educación en valores, Carta de la Tierra, ecopedagogía e innovación.

\section{SUMMARY}

The Earth Charter is a civil society initiative that aims to strengthen the value of sustainability and interdependence between people and their contexts (Gorbachev, 2006). This statement, endorsed by UNESCO, is considered a valuable educational tool in international projects such as the Decade of Education for Sustainable Development (2005-2014) promoted by United Nations. This work focuses on the study, through a methodology based on the content analysis of various international experiences taking the Earth Charter as a benchmark for innovation in Higher Education.

Our results bring us closer to the action taken, the nature of the motivation that makes them possible, the progress made, the degree of commitment of the actors and communities involved, while providing keys to advance the development of new initiatives Higher Education more committed to sustainability.

Key words: sustainable education, values education, Earth Charter, eco-pedagogy and innovation.

\section{SOMMAIRE}

La Charte de la Terre est une initiative de la société civile qui vise à renforcer la valeur de la durabilité et de l'interdépendance entre les personnes et leurs contextes (Gorbachev, 2006). Cette déclaration, adoptée par l'UnESCO, est considéré comme un outil pédagogique précieux à des projets internationaux tels que la Décennie pour l'éducation en vue du développement durable (2005-2014) promue par les Nations Unies. Ce travail se concentre sur l'étude, à travers une méthodologie basée sur l'analyse du contenu des diverses expériences internationales prenant la Charte de la Terre comme une référence pour l'innovation dans l'enseignement supérieur.

Nos résultats nous rapprochent de l'action entreprise, la nature de la motivation qui les rend possibles, les progrès réalisés, le degré d'engagement des acteurs et des communautés concernées, tout en fournissant des clés pour faire avancer le développement de nouvelles initiatives en l'enseignement supérieur plus engagées envers la durabilité.

Mots clés: l'éducation durable, l'éducation aux valeurs, Charte de la Terre, ecopédagogie et de l'innovation. 


\section{INTRODUCCIÓN}

Son numerosos los esfuerzos sociales que, promovidos por Naciones Unidas, se han emprendido para fomentar un mundo sostenible. Como sostienen Gutiérrez, Benayas y Calvo (2006), el Decenio de las Naciones Unidas de la Educación para el Desarrollo Sostenible 2005-2014 está siendo una oportunidad para incentivar e implicar a personas, colectivos e instituciones en la búsqueda de un mundo sostenible. La Carta de la Tierra como marco de intenciones inspirador, que trata de ir más allá de la teoría plasmando los propósitos en acciones que involucren al conjunto de la sociedad civil, es un ejemplo.

Tras 10 años desde la difusión de la Carta, con motivo del décimo aniversario de la misma y a medio camino del Decenio de Educación Sostenible 2005-2014, creemos necesario analizar cuáles son los cambios y experiencias innovadoras realizadas, hacer balance del camino recorrido para reflexionar acerca de las acciones emprendidas, los avances alcanzados y reforzar estos logros con compromisos futuros que contribuyan a mejorar la Educación Superior. En esta línea se encuentran las experiencias contempladas en la página web de la Carta de la Tierra (www.earthcharterinaction.org) desde diferentes lugares del planeta. Experiencias innovadoras entendidas "como un conjunto de ideas, procesos y estrategias, más o menos, sistematizados, mediante las cuales se trata de introducir y provocar cambios en las prácticas educativas vigentes" (Carbonell, 2002, 11). Se trata pues de un proceso que observa lo que sucede en las aulas, en la organización de los centros, en la vida de la comunidad educativa y en la cultura profesional del profesorado, para alterar y transformar el proceso de enseñanza-aprendizaje de modos muy diversos.

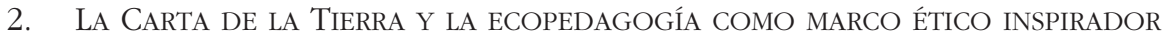

Compartimos un único mundo con un sinfín de culturas diferentes en el que cada vez viven más personas, menos unidas (Pérez, 1998) e insensibles a los problemas que afectan al planeta. En este escenario surge un movimiento, desde la sociedad civil, cuyo objetivo es crear una red de personas, instituciones, colectivos y organizaciones que configuren un marco de análisis y actuación desde el que concentrar y compartir esfuerzos, principios y valores, en pro de un mundo sostenible. Es así como, después de un continuado proceso de reuniones, diálogos y convenciones, personalidades internacionales influyentes (Mijail Gorbachov, Leonardo Boff, Mercedes Sosa, Amadou Toumani Touré y Wangari Maathai, entre otros) deciden explicitar los principios en un documento original cuyo texto se publica en el año 2000, y al que denominan "Carta de la Tierra". Esta red tiene entre sus objetivos: concienciar sobre los graves problemas ambientales a los que nos enfrentamos; guiarnos y ofrecernos ejemplos éticos de cómo cambiar nuestros comportamientos, pensamientos y actitudes; favorecer una conciencia planetaria inclusiva por la que todos sintamos que somos seres interdependientes 
en comunidad; reconocer a los grupos y a las personas sus esfuerzos en pro de la salud de nuestro planeta, y apoyar el uso educativo de la Carta de la Tierra en escuelas, universidades, comunidades locales y otros entornos (Boff, 2006). Pero lo que le configura un carácter innovador a esta declaración de principios no es que luche en pro de un mundo sostenible, pues antes de su difusión ya existían otros acuerdos y documentos con fines similares, sino que lo hace instando a los sentimientos, a la empatía y a la responsabilidad, apelando a la participación en la comunidad de la vida. De este modo, "la Carta de la Tierra constituye un documento único ya que refleja un nuevo nivel de comprensión compartida universalmente sobre la interdependencia entre los seres humanos y la naturaleza" (Gorbachev, 2006, 10).

Desde sus comienzos, la Carta de la Tierra ha suscitado interés y despertado la iniciativa de profesionales de diversas áreas. El ámbito educativo es una de las áreas con mayor potencial para la aplicación de sus principios y un medio único para aprender a ser responsables, cuidadosos y conscientes de las consecuencias que nuestros actos tienen en el contexto en el que nos encontramos inmersos y en el futuro de las generaciones venideras. Como señala Naranjo (2004), en nuestros tiempos actuales de transformación se reconoce que la educación constituye nuestra esperanza, es decir, la innovación de la educación es el mejor instrumento con el que contamos para lograr el cambio hacia un futuro sustentable.

La importancia de la Carta de la Tierra y sus repercusiones a nivel educativo no dejan impasibles al alumnado, profesorado, centros, organizaciones e instituciones, por lo que en la última década se han sucedido experiencias por toda la geografía mundial con distintas finalidades y trayectorias.

El desarrollo de la Carta de la Tierra en el ámbito de la Educación Superior no sólo exige de nuevos compromisos personales e institucionales, sino del desarrollo de una nueva pedagogía que ponga el énfasis en el desafío de crear una sociedad sostenible, pacífica y justa, en armonía con la Tierra y sus formas de vida, ésta es la ecopedagogía.

La ecopedagogía o pedagogía de la Tierra, al igual que la Carta de la Tierra, surge como un movimiento social en el Foro Global Mundial del 92, aunque anteriormente, en la década de los 70, el pedagogo Paulo Freire intuyera que se debía incluir el planeta como un componente esencial en nuestras relaciones y comenzara a asentar las bases de este nuevo compromiso educativo. Por ello, no es extraño que componentes fundamentales del Instituto Paulo Freire, como Moacir Gadotti o Francisco Gutiérrez, se hayan unido a esta nueva concepción ecocéntrica.

Posteriormente, se ha profundizado dando lugar en esta nueva relación con la Tierra, incorporando visiones ligadas a tradiciones indígenas como la expresada por el jefe Seatle (1855): "Enseñad a vuestros hijos lo que nosotros hemos enseñado a los nuestros: la Tierra es nuestra madre. Lo que afecte a la Tierra, afectará también a los hijos de la Tierra. Si los hombres escupen a la Tierra, se escupen a sí mismos. Porque nosotros sabemos esto: la Tierra no pertenece al hombre, sino el hombre a la Tierra. Todo está relacionado como la sangre que une a una familia". 
Desde esta perspectiva, más compleja, de la educación se plantea la necesidad de sustituir la visión intrapersonal y antropocéntrica por otra más holística y ecocéntrica (Morin, 1999; Gómez-Heras, 2000). La ecopedagogía nos aporta esa visión, puesto que trata de integrar puntos de vista alternativos, contemplando las necesidades del planeta y las de los seres que lo habitan, teniendo en cuenta la evolución de la realidad y la diversidad. Además, nos inculca un sentimiento de esperanza y valentía, pues acepta la realidad y pacientemente se enfrenta a los retos y problemas de la sociedad, evitando el desánimo y la pasividad (Zingaretti, 2001).

Este tipo de pedagogía asume la visión feminista de la ética del cuidado y de la compasión, se compromete con la interculturalidad, respeta los derechos humanos, los derechos de los niños (económicos, culturales, políticos y ambientales) y los derechos del planeta. Exige la práctica real y promueve la ciudadanía planetaria, para construir una civilización con un modo de vida responsable, respetuoso y cuidadoso con el medio. En este sentido, la ecopedagogía se presenta como una nueva pedagogía de los derechos que desarrolla la capacidad de deslumbramiento y de reverencia ante la complejidad del mundo y la vinculación con la Tierra.

Las exigencias de la sociedad planetaria deben ser trabajadas pedagógicamente a partir de la vida cotidiana desde la experiencia, pues "los valores se aprenden en y desde la experiencia" (Ortega y Romero, 2009, 174). Educar para la ciudadanía planetaria supone el desarrollo de nuevas capacidades: sentir, intuir, emocionarse, imaginar, crear, relacionarse, interconectarse, comunicarse, expresarse, procesar, criticar, evaluar, tomar decisiones, amar... que deben llevarnos a pensar globalmente y actuar conforme a una conciencia planetaria. La ecopedagogía hace uso de las formas múltiples de conocer (Gadotti, 2008). No sólo lo intelectual, sino también lo físico, social, moral, estético y, en un sentido no sectario, lo espiritual; así pues, es un tipo de ecología integral que contempla la relación con el medio, con los demás e implica un nuevo paradigma político, cultural, económico y espiritual. "Esta nueva ética medioambiental exige no sólo ampliar las relaciones morales con los demás más allá de las relaciones inmediatas yo-tú, sino también entenderlas en el inevitable contexto de las relaciones con, en y a través de la naturaleza o medio" (Ortega y Romero, 2009, 169). Esta visión forma parte de una educación transformadora, con un enfoque integral, holístico de la vida y del aprendizaje: más allá de lo cognitivo, pero integrándolo, está lo vivencial-experiencial y lo emocional. No aprendemos a amar la Tierra sólo leyendo libros que versen sobre ella, ni observando imágenes, la experiencia propia transciende lo cognitivo y nos acerca a otros niveles de compromiso. La cantidad de información de la que disponemos no ha derivado en modelos respetuosos con el medio que nos rodea.

El paradigma de la razón instrumental o positivista no nos ha conducido a la paz con el medio, pues se niegan los valores y las dimensiones humanas fundamentales como la intuición, las emociones o la sensibilidad (Noguera, 2004). Sí a la razón, pero no como criterio único y principal. "Esta racionalidad está en el origen de la crisis ambiental que nos afecta. La naturaleza ya no es vista como un valor o sujeto de aprecio, sino como objeto de dominio" (Ortega y Romero, 2009, 169). 
La ecopedagogía promueve una racionalidad intuitiva y comunicativa, afectiva, no instrumental, moral, reeducando el mirar, desde el corazón. Es una educación para una ciudadanía planetaria que tiene por finalidad la construcción de una cultura de la sustentabilidad, una cultura de paz para la vida, de convivencia armónica entre los seres humanos y con el planeta. Esto nos debe llevar a seleccionar lo que es realmente sustentable y ético en nuestras vidas.

La búsqueda incansable de un desarrollo más sostenible, el deseo de un cambio de conciencia a escala planetaria que se apoye en una sentimiento de interdependencia (Fernández y López, 2010) y la apuesta por los principios de la Carta de la Tierra encuentran en la ecopedagogía una forma práctica de convertir todas estas intenciones en realidad (Fernández y Conde, 2010).

Educar para pensar de forma compleja e innovadora, enseñar teniendo en cuenta las emociones, crear conciencia planetaria, fomentar el respeto y el cuidado del planeta, y la paz con uno mismo y con los demás son algunos de los objetivos y de las características de esta nueva forma de ser (Fernández y Carmona, 2010). Como expresa Gadotti (2010), educar para lo sostenible significa educar para la emergencia de lo diferente, para la utopía y la concepción de otro posible mundo. Significa provocar cambios en la concepción y organización del conocimiento abogando por la interdisciplinariedad y la transversalidad, además de la presencia real de objetivos holísticos que contemplen todos los ámbitos de la persona (cognitivos, de procedimiento, afectivos, emocionales, espirituales...); donde el profesorado no cumpla sólo la misión de instruir ni la de formar, sino la de educar en valores, transformando su papel de instructor por el de facilitador del aprendizaje y sus metodologías de enseñanza por modos más activos, diversos y centrados en el alumnado; desde la flexibilización del proyecto educativo para que fortalezca la democracia, la participación y la apertura a la comunidad y a la familia.

Éste es un momento propicio para emprender y retomar la innovación como modo de solventar los problemas ecológicos desde la educación, ya que hasta ahora no habíamos tenido una conciencia tan clara de la catástrofe ecológica hacia la que nos dirigimos (Jiménez y López, 2007).

\section{Metodología}

En este trabajo se muestra un análisis de contenido de 16 casos internacionales innovadores que conforman el total de experiencias publicadas hasta la actualidad (Vilela, 2008 y www.earthcharterinaction.org), en las cuales se aplicaron de forma práctica principios y objetivos dentro del ámbito educativo, concretamente en la etapa de Educación Superior.

Como técnica para estudiar las experiencias se ha utilizado el análisis de contenido, entendido como "conjunto de técnicas de análisis de comunicaciones, tendentes a obtener indicadores por procedimientos sistemáticos y objetivos de descripción de mensajes, permitiendo la inferencia de conocimientos relativos a las condiciones de producción/recepción variables inferidas de esos mensajes" 
(Bardín, 1986, 364) y nos hemos valido del programa QSR NVivo 8.0. En este estudio se presentan las categorías que sirven de base al análisis, extraídas tras un proceso mixto de inducción y deducción, pues han emergido de la lectura e interpretación de 16 experiencias llevadas a cabo en la etapa de Educación Superior, y de la revisión bibliográfica realizada para definir y contemplar qué aspectos se consideran innovadores y sostenibles. Posteriormente, se ha procedido al análisis cruzado de la información de categorías entre sí y de éstas con los atributos mediante matrices de codificación. En los resultados se presentan únicamente las matrices más significativas, en forma de gráficos.

Las categorías extraídas se definen del siguiente modo: Motivación: categoría referida a la naturaleza del estímulo que dio origen al diseño y desarrollo de la experiencia. Participantes: agentes involucrados, directa o indirectamente, desde el diseño de la experiencia. Objetivos: tipología de propósitos que se persiguen con las experiencias. Contenidos: temáticas abordadas en las experiencias analizadas. Metodología: recoge los aspectos referidos a las estrategias, formas de actuar y procedimientos empleados en el desarrollo de la experiencia. Actividades: tareas emprendidas para alcanzar los objetivos propuestos. Diseño, Desarrollo y Evaluación: aspectos relativos a la forma en que se ha llevado a cabo la planificación y puesta en marcha de la experiencia. Recursos: medios utilizados en las experiencias. Y, por último, Compromisos: categoría que alude a las acciones y propuestas para el futuro con las que se comprometen los implicados en las experiencias.

\subsection{Descripción de las experiencias}

Las experiencias publicadas se desarrollan en todos los continentes de la Tierra, aunque la mayoría se concentran en América y Europa. De las dieciséis experiencias analizadas, siete se desarrollan en América, cuatro en Europa, dos en Asia, dos en África y solamente una en Oceanía.

GRÁFICO 1. LOCALIZACIÓN DE LAS EXPERIENCIAS

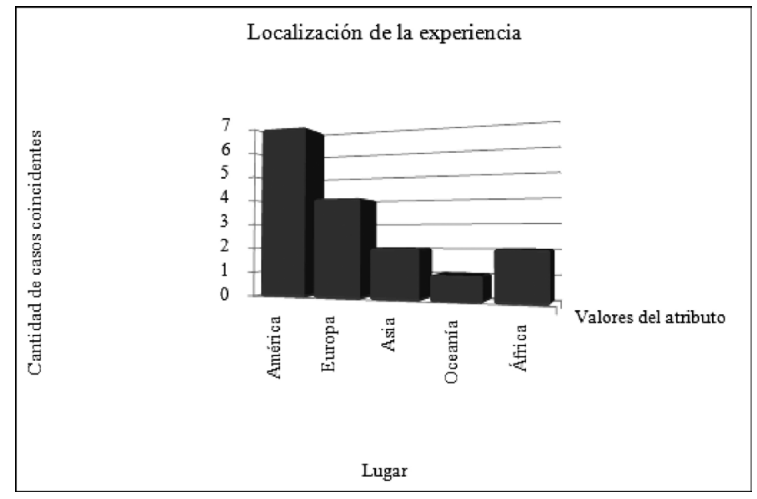


Atendiendo al ámbito de aplicación de las experiencias, se observa una gran diferencia entre las experiencias que se desarrollan a nivel de centro y las que lo hacen en el resto de ámbitos. Once de las quince experiencias se realizan en el centro; de las cinco restantes, dos se llevan a cabo a nivel local-regional, una en el aula, otra a nivel nacional y la última a nivel internacional.

GRÁFICO 2. ÁmBiTOS DE LAS EXPERIENCIAS

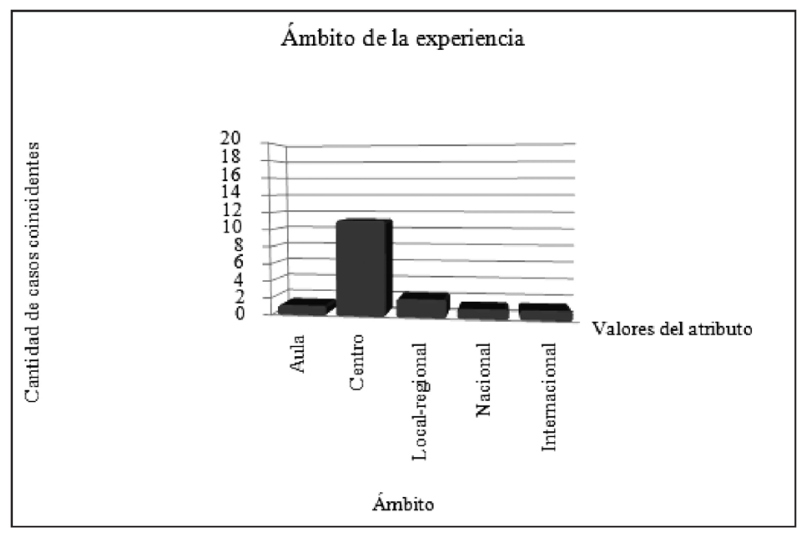

Centrándonos en la duración de las experiencias, se puede ver que diez de ellas tienen una duración mayor de un año, una menor y en cinco de las mismas no se alude en ningún momento al tiempo previsto para desarrollar la experiencia. Esto refleja que las experiencias tienen un carácter continuado en el tiempo, por lo que no son actividades puntuales y aisladas en el tiempo.

GRÁFICO 3. DURACIÓN DE LAS EXPERIENCIAS

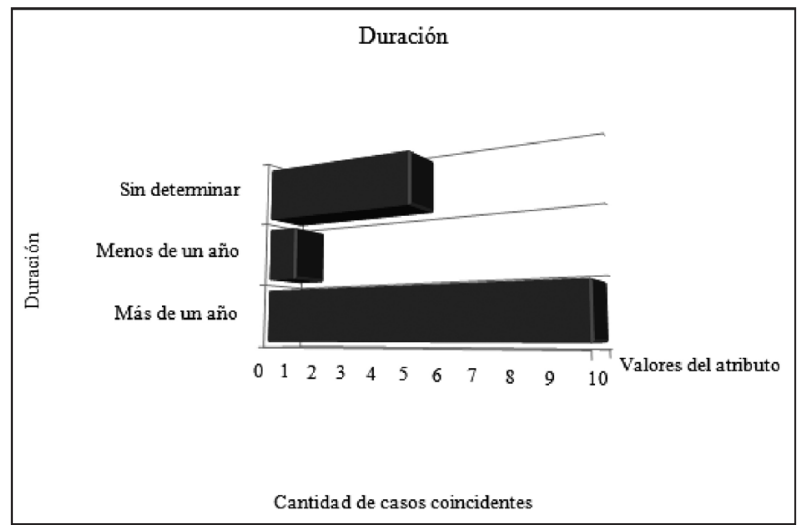


Por otro lado, como se aprecia en el Gráfico 4, no existen diferencias significativas entre las experiencias que tienen en cuenta varias disciplinas y aquellas otras que sólo se inician desde una única disciplina, ya que ocho de las dieciséis experiencias analizadas tienen carácter pluridisciplinar y siete unidisciplinar. Únicamente en una de las iniciativas no se especifica el carácter de la misma.

\section{GRÁFICO 4. DisCIPLINAS DESDE LAS QUE SE ORIGINAN LAS EXPERIENCIAS}

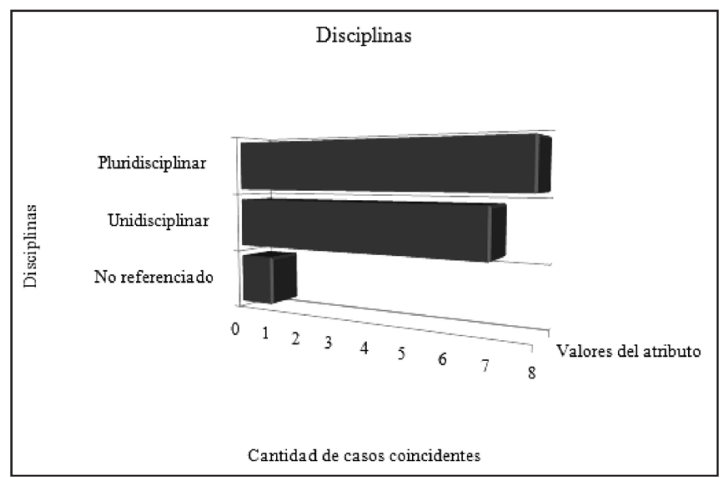

\section{Resultados}

A continuación se presentan los resultados obtenidos, una vez realizado el análisis de contenido de los textos de las experiencias, distinguiendo entre análisis de categorías en función del recuento por casos concretos (F1) y en función de la frecuencia de menciones total en el global de casos (F2).

\subsection{Motivación}

TABLA 1. MOTIVACIÓN

\begin{tabular}{|c|c|c|c|}
\hline CATEgORÍA & SUBCATEGORÍA & F1 & F2 \\
\hline \multirow{3}{*}{ Motivación } & Extrínseca & 4 & 4 \\
\cline { 2 - 4 } & Intrínseca & 9 & 14 \\
\cline { 2 - 4 } & Mixta & 1 & 1 \\
\hline
\end{tabular}

Centrándonos en la categoría motivación, se observa que la naturaleza del estímulo que da origen al diseño y desarrollo de estas experiencias es básicamente de naturaleza intrínseca, como así lo evidencia la elevada frecuencia alcanzada 
tanto en la F1 como en la F2. En menor medida figura la motivación extrínseca o de doble naturaleza (extrínseca-intrínseca).

Profundizando en el contenido de las menciones de naturaleza intrínseca, se aprecia que éstas tienen un doble carácter, por una parte, nacen de la iniciativa de los propios individuos.

La profesora Karine Danielyan ha sido educadora toda su vida. Decidió hacer desarrollo sustentable -una novedad semántica muy controversial a principios de los noventas-, como parte de su personalidad en la enseñanza en 1994. Tomó una fuerte decisión al renunciar a su puesto en el Ministerio Ambiental en el primer gobierno democrático post-soviético de la Armenia independiente, y regresar a la academia, su antigua profesión. La decisión le costó muchas noches sin dormir, así como acaloradas discusiones con miembros del gobierno armenio, con amigos y colegas. Fue una difícil decisión, ya que había representado a su país en la Cumbre de Río en 1992 y estaba comprometida con la Agenda 21 como plan de gobierno, planeación y política (Bakhnova, 2008, 131).

Por otra, son fruto de un grupo social o una institución. "La Universidad Nacional de Costa Rica (UNA) está comprometida en poner en práctica los principios de la Carta de la Tierra en la administración y políticas de su campus, en sus actividades académicas y extensión de proyectos" (Jiménez, Cedeño, Salas, San Lee, Peña, Vega, Sánchez y Zamora, 2008, 113).

\subsection{Participantes}

La categoría participantes se subdivide en las siguientes subcategorías: profesor-alumno, comunidad educativa y agentes educativos externos.

TABla 2. PARTICIPANTES

\begin{tabular}{|c|c|c|c|}
\hline CATEGoría & SubCatEgORÍA & F1 & F2 \\
\hline \multirow{3}{*}{ Participantes } & Agentes educativos externos & 5 & 8 \\
\cline { 2 - 4 } & Comunidad educativa & 5 & 5 \\
\cline { 2 - 4 } & Profesor-Alumno & 11 & 19 \\
\hline
\end{tabular}

En la mayoría de experiencias, once de dieciséis con un total de diecinueve menciones, los participantes fueron el profesorado y el alumnado. "Primero empezamos con tres grupos de 40 estudiantes de segundo año del curso de Ciencias de actividades físicas y deportes, y tres profesores (jugando el rol de facilitadores-tutores) de la Universidad de Lleida" (Legardera, 2008, 156). Las subcategorías, agentes educativos externos y comunidad educativa, se encuentran equilibradas con respecto a su presencia en las experiencias (F1: cinco-cinco 
respectivamente) y en el número de referencias que derivan de ellas (F2: ochocinco respectivamente).

Si se analiza esta información según los continentes donde tienen sede las experiencias, en el Gráfico 5, se comprueba que en todos ellos existen algunas experiencias cuyos participantes son el profesorado y el alumnado, en la mayoría también tienen en cuenta a determinados agentes externos, pero sólo en América y Europa se dan casos que incluyan a toda la comunidad. A continuación se muestra un extracto representativo de la experiencia americana donde se considera a la comunidad educativa: "Nuestros eventos incluyen las dos series de lecturas para los estudiantes, facultad y personal de la universidad y para el público del suroeste de Florida" (Blaze y Wohlpart, 2008, 121). Como comunidad educativa no sólo se ha considerado al profesorado, el alumnado y el personal administrativo sino también a las familias de los estudiantes. Por otro lado, se consideran agentes educativos externos, por ejemplo, cuando participan asociaciones como se produjo en Yeveran (Armenia), ayuntamiento como en el caso de Lleida (España), empresas como en Mendeleyev (Rusia), etc.

GRÁFICO 5. PARTICIPANTES Y LUGAR

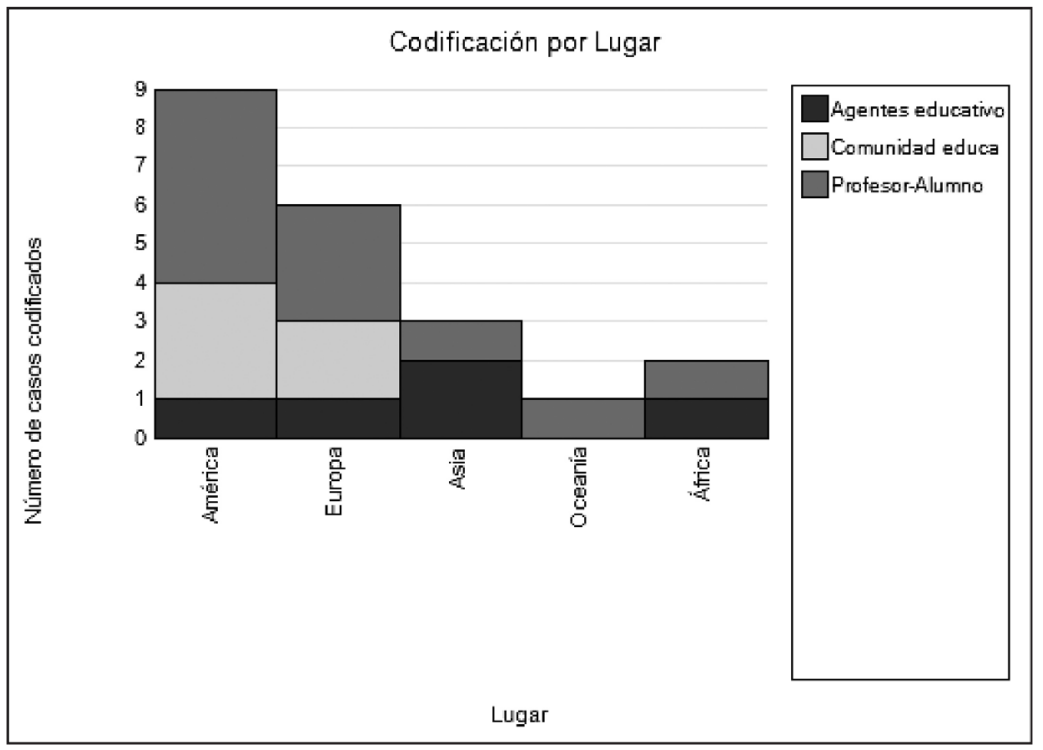

En el Gráfico 6 se reitera cómo la subcategoría profesor-alumno tiene una mayor presencia tanto a escala micro, en los niveles de aula o de centro, como a escala macro en los niveles nacional e internacional. La excepción es a nivel localregional donde tiene presencia la comunidad educativa. 
GRÁFICO 6. PARTICIPANTES Y ÁMBITO

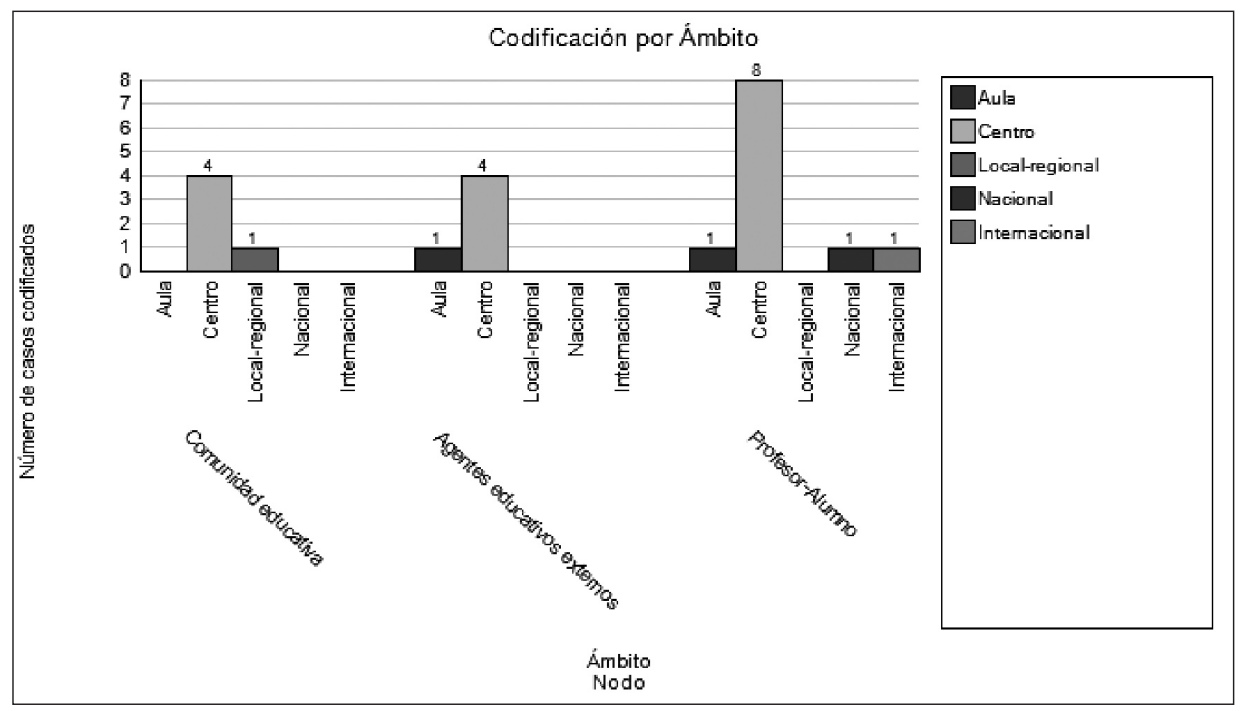

\subsection{Objetivos}

Dentro de la categoría objetivos se incluyen los de tipo cognitivo, de procedimiento, actitudinales y afectivo-emocionales.

TABLA 3. OBJETIVOS

\begin{tabular}{|c|c|c|c|}
\hline CAtEgORÍA & SubCATEGoría & F1 & F2 \\
\hline \multirow{4}{*}{ Objetivos } & Cognitivos & 5 & 5 \\
\cline { 2 - 4 } & De procedimiento & 10 & 23 \\
\cline { 2 - 4 } & Actitudinales & 13 & 23 \\
\cline { 2 - 4 } & Afectivo-Emocionales & 5 & 9 \\
\hline
\end{tabular}

En relación a los objetivos se comprueba que los de procedimiento y los actitudinales tienen una mayor F2, ambos con veintitrés menciones, con una ligera presencia en más experiencias de la subcategoría actitudinales, pues aparecen en trece de ellas mientras que los de procedimiento aparecen en diez.

La mayoría de objetivos actitudinales pretenden provocar cambios hacia actitudes más activas, críticas, éticas y respetuosas con el medio y la sostenibilidad. "La lección principal es encontrar soluciones a la crisis ambiental, al cambiar nuestra manera de pensar, así como promover los valores de solidaridad, respeto 
y colaboración" (Jiménez, Cedeño, Salas, San Lee, Peña, Vega, Sánchez y Zamora, 2008, 115).

En general, los objetivos de procedimiento pretenden implementar o desarrollar cursos de formación o planes de estudios, introducir pautas sostenibles y elaborar recursos de diferente índole. "El objetivo central del programa es implementar un sistema integral y sustentable para los desperdicios; tratamiento de aguas y conservación de energía dentro de la universidad" (Jiménez, Cedeño, Salas, San Lee, Peña, Vega, Sánchez y Zamora, 2008, 114).

A una distancia significativa se hallan las subcategorías afectivo-emocionales y cognitivos que sólo aparecen en cinco de las dieciséis experiencias analizadas. Con respecto a los objetivos afectivo-emocionales, pretenden crear un lazo entre las personas y la naturaleza o, lo que es lo mismo, entre la comunidad de la vida. "Fomento de la colaboración y las buenas relaciones entre comunidades dentro y fuera del campus" (Robson, 2008, 142). Los propósitos de los objetivos cognitivos en estas experiencias son adquirir conocimiento sobre las causas de la degradación de nuestro medio, conocer la Carta de la Tierra y aportar una noción básica de sustentabilidad.

\subsection{Contenidos}

Esta categoría se centra en las temáticas concretas que abordan las experiencias. Contiene los siguientes temas: Ambientales-Ecológicos, Diversidad cultural, Ética, Valores y Derechos Humanos y Organización política y justicia social y económica.

\section{TABla 4. CONTENidos}

\begin{tabular}{|c|c|c|c|}
\hline CATEGORÍA & SubCATEGORÍA & F1 & F2 \\
\hline \multirow{4}{*}{ Contenidos } & Ambientales-Ecología & 8 & 18 \\
\cline { 2 - 4 } & Diversidad cultural & 4 & 5 \\
\cline { 2 - 4 } & Ética-Valores (Paz)-Derechos Humanos & 7 & 16 \\
\cline { 2 - 4 } & $\begin{array}{c}\text { Organización política-Democracia- } \\
\text { Justicia Social y Económica }\end{array}$ & 6 & 15 \\
\hline
\end{tabular}

La tabla precedente muestra los contenidos que abordan temas ambientalesecológicos como los más referenciados (F2: dieciocho) en las experiencias, seguidos por aquellos que versan sobre ética, valores, derechos humanos (F2: dieciséis), después por los de organización política, democracia y justicia social y económica (F2: quince), y, en último lugar, los que tratan sobre la diversidad cultural (F2: cinco). La frecuencia por casos (F1) sigue el mismo orden descendiente.

Cuando hablamos de contenidos ambientales-ecológicos se hace referencia a aspectos como nociones sobre el cambio climático, el desarrollo sostenible, la 
salud ambiental, políticas ambientales, etc. "Los eventos se enfocan en los tópicos generales de agricultura y ética, con discusiones específicas sobre justicia social, salud ambiental, condiciones de trabajo para producir alimento en América y el trato de los humanos hacia los animales que sirven como alimento" (Blaze y Wohlpart, 2008, 121).

Los contenidos sobre ética, valores y derechos humanos y los contenidos sobre organización política, democracia y justicia social y económica aparecen muy relacionados, eso puede explicar que la F1 y la F2 sean similares. "A los asistentes se les presentan programas de temas como la sustentabilidad, democracia y justicia, las metas de la sustentabilidad, la reorientación de la educación existente hacia el desarrollo sustentable, y las mejores prácticas pedagógicas y experiencias a nivel nacional e internacional" (Tarasova y Zaitsev, 2008, 165).

Los temas referentes a la diversidad cultural aparecen de forma superficial, en escasas ocasiones y en pocas experiencias. "Los proyectos en que los estudiantes han enfocado su interés son de tipo ecológico, social y cultural" (Jiménez y Martín, 2008, 127).

\subsection{Metodología}

La metodología engloba las siguientes subcategorías: centrada en el estudiante, diversificada, enfoque transversal-interdisciplinar y metodología activo-participativa.

\section{TABla 5. Metodología}

\begin{tabular}{|c|c|c|c|}
\hline CATEGORÍA & SuBCATEGORÍA & F1 & F2 \\
\hline \multirow{4}{*}{ Metodología } & Centrada en el estudiante & 7 & 13 \\
\cline { 2 - 4 } & Diversificada & 4 & 4 \\
\cline { 2 - 4 } & Enfoque transversal-Interdisciplinar & 10 & 15 \\
\cline { 2 - 4 } & Metodología activo-participativa & 13 & 31 \\
\hline
\end{tabular}

Tomando como referencia las estrategias, formas de actuar y procedimientos empleados en el desarrollo de la experiencia, se encuentra que la subcategoría metodología activo-participativa, con una F1 de trece y una F2 de treinta y uno, es el procedimiento más utilizado. "La orientación del curso enfatiza participación activa y el significado de la historia y contexto en el proceso educativo" (Olvitt, Sisitka y Schudel, 2008, 148).

En segundo lugar, con una F1 de diez y una F2 de quince menciones figura la subcategoría enfoque transversal-interdisciplinar.

El Instituto de Química y Problemas en Desarrollo Sustentable en la Universidad Mendeleyev utiliza las siguientes características del proceso educativo: Acercamiento interdisciplinario, que implica la combinación de formas de educación tradicional con ideas y metodologías innovadoras. Los químicos jóvenes aprenden 
de química junto con cursos especiales de desarrollo sustentable y de evaluación y manejo de riesgo ambiental, así como de patrones de producción y consumo sustentables (Tarasova y Zaitsev, 2008, 167).

Este enfoque integral ofrece una perspectiva holística de la realidad ambiental educativa, pues de modo horizontal temas ambientales atraviesan transversalmente todas las áreas del currículo formal y oculto.

En cuanto a la metodología centrada en el estudiante, presente en siete experiencias con trece menciones, se observa cómo el sistema se adapta a los participantes, partiendo de sus intereses, sus necesidades, sus estilos de aprendizaje, cuidando que existan diversos materiales, etc. "Al inicio del proceso de la educación para el desarrollo sustentable, Michelle nota que también es importante ser sensible, y tomar en cuenta los intereses de cada estudiante" (Jiménez y Martín, 2008, 130).

En último lugar, nos encontramos con la subcategoría diversificada, más alejada del resto de metodologías contempladas, con cuatro menciones en las experiencias de Auckland (Nueva Zelanda), Florida (Estados Unidos), Mendeleyev (Rusia) y Seychelles (África). El tipo de diversificación que se encuentra en estas experiencias se canaliza a través del uso de diferentes métodos o estrategias de enseñanza, de diferentes tipos de actividades combinadas y de acciones diversas en distintos niveles del currículo.

En el gráfico que mostramos a continuación, se encuentra cómo la metodología activa y los enfoques interdisciplinares se dan en la mayoría de ámbitos donde se dan las experiencias, sin embargo, únicamente se tienen en cuenta metodologías centradas en los alumnos en experiencias a nivel logal-regional y de centro, mientras que los procesos metodológicos más diversificados sólo a nivel de centro.

GRÁFICO 7. METODOLOGÍA Y ÁMBITO

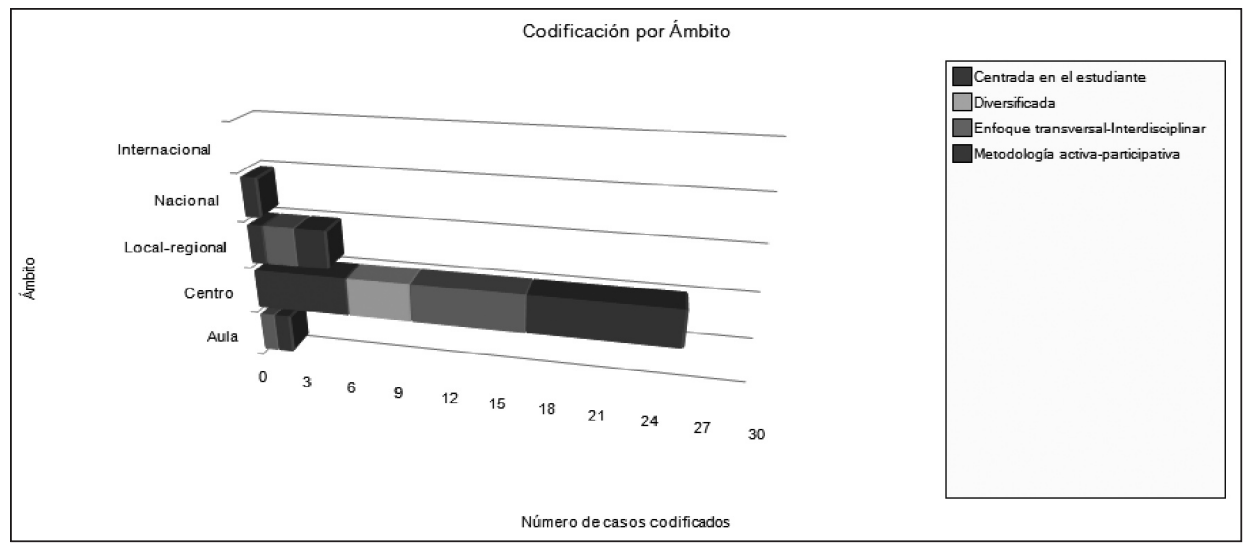




\subsection{ACTIVIDADES}

La categoría actividades es una de las más referenciadas en el conjunto general. Ésta se clasifica en: actividades de representación, actividades grupales, actividades individuales, clase magistral, actividades que combinan diferentes canales, que transcienden el aula, grupos de discusión, proyectos de discusión, actividades de carácter teórico, práctico o teórico-práctico.

TABLA 6. ACTIVIDADES

\begin{tabular}{|c|c|c|c|}
\hline CATEGORÍA & SubCATEGORÍA & F1 & F2 \\
\hline \multirow{4}{*}{ Actividades } & Actividades de representación & 8 & 20 \\
\cline { 2 - 4 } & Actividades grupales & 6 & 9 \\
\cline { 2 - 4 } & Actividades individuales & 7 & 11 \\
\cline { 2 - 4 } & Clase magistral & 4 & 9 \\
\cline { 2 - 4 } & Combinan distintos canales & 6 & 26 \\
\cline { 2 - 4 } & Grupos de discusión & 12 & 12 \\
\cline { 2 - 4 } & Prócticas & 7 & 8 \\
\cline { 2 - 4 } & Proyectos de investigación & 5 & 6 \\
\cline { 2 - 4 } & Teóricas & 5 & 7 \\
\cline { 2 - 4 } & Teórico-Prácticas & 8 & 18 \\
\hline
\end{tabular}

En la Tabla 6 se muestra como los grupos de discusión son, tanto por la F1 presentes en doce experiencias como por F2 con veintiséis menciones, la estrategia más usada en la mayoría de las experiencias de Educación Superior.

La clase de discusión da la oportunidad de articular estos puntos de vista y considera una profunda necesidad de cambiar la sociedad. No habrá, sin embargo, una cura rápida al problema, ya que el sistema económico y social necesita ser reconstruido sobre la responsabilidad compartida para la comunidad de la vida entera (seres humanos y todos los seres vivos) (Taylor y Bosselmann, 2008, 160).

Seguidamente, con mayor número de F1 (ocho) y de F2 (veinte), se hallan las actividades de representación, las cuales engloban actividades como representaciones teatrales, poesías, canciones, juegos de roles, etc.

Se escribió una obra de teatro hecha por estudiantes y maestros de teatro llamada "La Carta de la Tierra salva a la hermosa Tierra" que fue presentada en el Taller Regional en noviembre del 2000. Los estudiantes y sus padres hicieron disfraces llamativos y presentaron a los participantes del taller hermosas canciones y poemas dirigidos a la Tierra, naturales y al valiente caballero llamado La Carta de la Tierra -que salva a la Tierra del desastre enseñando a la gente cómo protegerla(Bakhnova, 2008, 134). 
Si se continúa analizando el tipo de actividades en función de la estrategia usada, la siguiente subcategoría con un mayor número de frecuencias es la de proyectos de investigación, presente en cinco experiencias con ocho referencias; $\mathrm{y}$, por último, la de clase magistral, con seis referencias repartidas en cuatro experiencias. Esto corrobora la escasa representatividad de las clases magistrales a la hora de llevar a cabo prácticas innovadoras, en contraposición al gran uso que se le da en clases cotidianas.

El segundo bloque de actividades, referido a los espacios físicos y canales de comunicación, es uno de los más referenciados. En la mitad de las experiencias (ocho) las actividades logran trascender el salón de clases e ir más allá.

Los estudiantes trabajaron en jardines escolares, programas de alfabetización, programas de tutoría para desfavorecidos, estudiaron estándares para edificios verdes, desarrollaron listas de productos reciclados, organizaron una conferencia regional universitaria sobre el calentamiento global, elevaron la conciencia de comer carne, estudiaron e hicieron representaciones con una campaña internacional de danza para la paz, etc. (Link, s/f).

Por otro lado, en seis experiencias se usan distintos canales de comunicación combinados para adaptarse a los diferentes estilos de aprendizaje de los heterogéneos participantes. "La Carta y la película se dan juntas en este curso, para reforzar una con la otra y crear un ímpetu poderoso para la acción ética acerca del cambio climático. Esta convergencia da como resultado un aprendizaje innovador, renovado y satisfactorio, aportando una experiencia nueva para estudiantes y maestros" (Taylor y Bosselmann, 2008, 161). Éste es un modo de propiciar que los contenidos se interioricen de un modo más potente y desarrollen diferentes inteligencias.

Si atendemos a las actividades en función del agrupamiento, predominan las actividades individuales con mayor número de menciones (F2) y con mayor presencia en las experiencias (F1). Éstas son seguidas de cerca por las actividades grupales, sin que se produzcan diferencias muy significativas entre ambas subcategorías. El contenido de las experiencias muestra que esto puede deberse a que antes de realizar una actividad grupal realizan algunas actividades preparatorias individuales para que luego puedan participar aportando su conocimiento y habilidades al grupo, como es el caso de la experiencia de Yeveran. "Ella comienza su curso dando un folleto de la Carta de la Tierra (en armenio, ruso e inglés) a los estudiantes para leerlo en casa" (Bakhnova, 2008, 133). O que tras la actividad grupal se permita a los participantes avanzar y profundizar de un modo individual y autónomo, como es el caso de la experiencia de México o la experiencia de España.

Una vez que los estudiantes estuvieron informados sobre los principios de la Carta, se les pidió escribir un periódico durante el curso dentro de un periodo académico, el cual define cada principio. Se les pidió a los estudiantes iniciar actividades en su vida diaria vistas desde la perspectiva de "Dignidad Humana". Cada estudiante 
debía captar estas acciones en su diario personal y empatar las acciones con los principios de los que habían escrito. Más tarde podían reflexionar del por qué las acciones fueron comparadas con esos principios (Fernández y Conde, 2008, 108).

El último grupo de actividades se analizará en función del carácter teórico, práctico y teórico-práctico. Dentro de este bloque, las actividades prácticas superan en la F1 como en la F2 a las de carácter teórico o teórico-práctico que se encuentran equiparadas. Las experiencias tienen un carácter eminentemente práctico, lo que podría contribuir a que los estudiantes tengan un rol más activo en su proceso de enseñanza y aprendizaje.

\subsection{Diseño, desarrollo y evaluación}

En esta categoría se estudian aspectos referentes al modo en que se ha puesto en marcha el diseño, el desarrollo de la experiencia y su evaluación. Se distingue entre las siguientes subcategorías: flexibilidad en la organización, carácter colaborativo del proceso, reconocimiento externo y evaluación.

TABla 7. Diseño, Desarrollo y EVALUACión

\begin{tabular}{|c|c|c|c|}
\hline CATEGORÍA & SubCATEGORía & F1 & F2 \\
\hline \multirow{3}{*}{$\begin{array}{c}\text { Diseño, } \\
\text { desarrollo }\end{array}$} & Especifica la evaluación & 4 & 7 \\
\cline { 2 - 4 } y evaluación & Organización flexible & 6 & 7 \\
\cline { 2 - 4 } & Proceso colaborativo-carácter democrático & 7 & 14 \\
\cline { 2 - 4 } & $\begin{array}{c}\text { Reconocimiento externo } \\
\text { (financiación, apoyos, recursos) }\end{array}$ & 6 & 11 \\
\hline
\end{tabular}

La tabla precedente muestra que un proceso colaborativo y de carácter democrático sería importante para el diseño y desarrollo de las experiencia innovadoras, pues aparece en siete experiencias con catorce menciones, situándose como la subcategoría con mayor número de referencias. "El proceso contó con la participación de la Universidad en un diálogo abierto para el futuro de la educación profesional, particularmente en el contexto del régimen de proyectos de estudios Universitarios Trans-Europeos" (Belousa y Micule, 2008, 170).

Con una presencia en seis experiencias el reconocimiento externo es la subcategoría más mencionada. Se considera reconocimiento externo al apoyo económico, social, institucional, etc. En las experiencias se evidencia una mayor presencia de reconocimientos de tipo social e institucional que de tipo económico. «En el 2003, el diario recibió reconocimiento oficial de la Academia de Ciencias de Letonia (Concejo de Ciencias) y fue incluido en la lista de reconocimientos universales para ser revalorados por las ediciones científicas" (Belousa y Micule, 2008, 172). 
Con igual número de menciones en la F1 (seis) pero menores menciones en la F2 (siete) que la anterior, encontramos la subcategoría organización flexible. Ésta hace referencia a la capacidad de adaptación y transformación de la organización atendiendo a las circunstancias. "Anteriormente, los estudiantes recibían un conjunto estandarizado de asuntos locales -como desperdicios, deforestación, pérdida del hábitat- para elegir, pero ahora el curso ha sido rediseñado para que los estudiantes elijan su propia área de interés" (Jiménez y Martín, 2008, 127).

Con respecto a la evaluación, comprobamos que se especifica en pocas experiencias y con pocas menciones (F1: cuatro). En el caso de la experiencia de Brasil la evaluación tiene carácter formal, mientras que en las experiencias de Lleida, Rodhes y Seychelles el proceso evaluativo es informal.

\subsection{Recursos}

La categoría recursos permite distinguir entre: autogenerados, estandarizados, naturales, reciclados y tecnológicos.

TABla 8. Recursos

\begin{tabular}{|c|c|c|c|}
\hline CATEGORÍA & SubCATEGORÍA & F1 & F2 \\
\hline \multirow{4}{*}{ Recursos } & Autogenerados & 6 & 10 \\
\cline { 2 - 4 } & Estandarizados & 12 & 31 \\
\cline { 2 - 4 } & Naturales & 1 & 1 \\
\cline { 2 - 4 } & Reciclados & 2 & 4 \\
\cline { 2 - 4 } & Tecnológicos & 9 & 19 \\
\hline
\end{tabular}

De acuerdo con las frecuencias alcanzadas se observa que los recursos más empleados en el conjunto de las experiencias son los estandarizados, con una presencia en doce experiencias y treinta y una menciones en el cómputo total de las iniciativas desarrolladas. El recurso estandarizado más empleado es el documento de la Carta de la Tierra, que se usa como herramienta material para explicar sus contenidos y principios. "La Carta es utilizada para retar a los estudiantes para considerar la interdependencia de la existencia humana en la Tierra, y el rol en la ética al llevar un cierto tipo de comportamiento, reestructurando el contenido de los sistemas de gobierno y legales" (Taylor y Bosselmann, 2008, 160).

En un segundo nivel figuran los recursos tecnológicos (F1: nueve, F2: diecinueve), como páginas webs, foros, tutores virtuales..., que complementan otros recursos y permiten dar más difusión a las experiencias, además de abrirse a una comunidad más amplia en menor tiempo, etc. "Como resultado directo de esta propuesta, se instaló una página web para ofrecer estos recursos educativos para el beneficio de todos y así ser usados por un sector mayor en la comunidad educativa" (Fernández y Conde, 2008, 109). 
Con respecto a los recursos autogenerados podemos decir que se han creado y usado para las actividades multitud de materiales diversos, como: libros, páginas webs, presentaciones fotográficas, foros, folletos, revistas, etc.

En último lugar, con menor presencia, se encuentran los recursos reciclados y los recursos naturales. Se hacen menciones a recursos reciclados en la experiencia de Wisconsin o de la reutilización de juguetes en la experiencia de Granada. "La Feria de Juguetes está diseñada para ofreces juguetes usados -en buenas condiciones, no-bélicos ni sexistas- a los niños" (Fernández y Conde, 2008, 110). El recurso natural empleado fue el agua y la luz natural en la experiencia de Wisconsin Oshkosh, en Estados Unidos.

En los siguientes gráficos se muestra la relación entre los recursos y el ámbito y los recursos y el tipo de actividades.

GRÁFICO 8. RECURSOS Y ÁMBITO

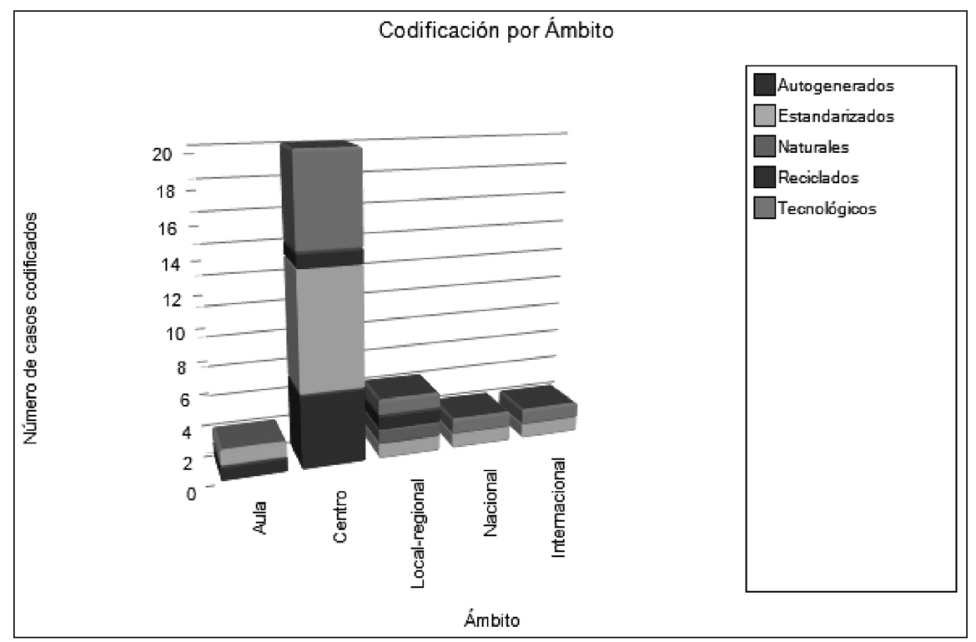

Correlacionando el ámbito en que se desarrollan las experiencias y los recursos, encontramos que los recursos estandarizados se emplean en todos los ámbitos, mientras que los autogenerados sólo a nivel micro, en el aula y el centro. A nivel macro, nacional e internacional, coincide el uso de recursos tecnológicos y estandarizados. Mientras que los recursos naturales tienden a emplearse en el escenario local-regional. 


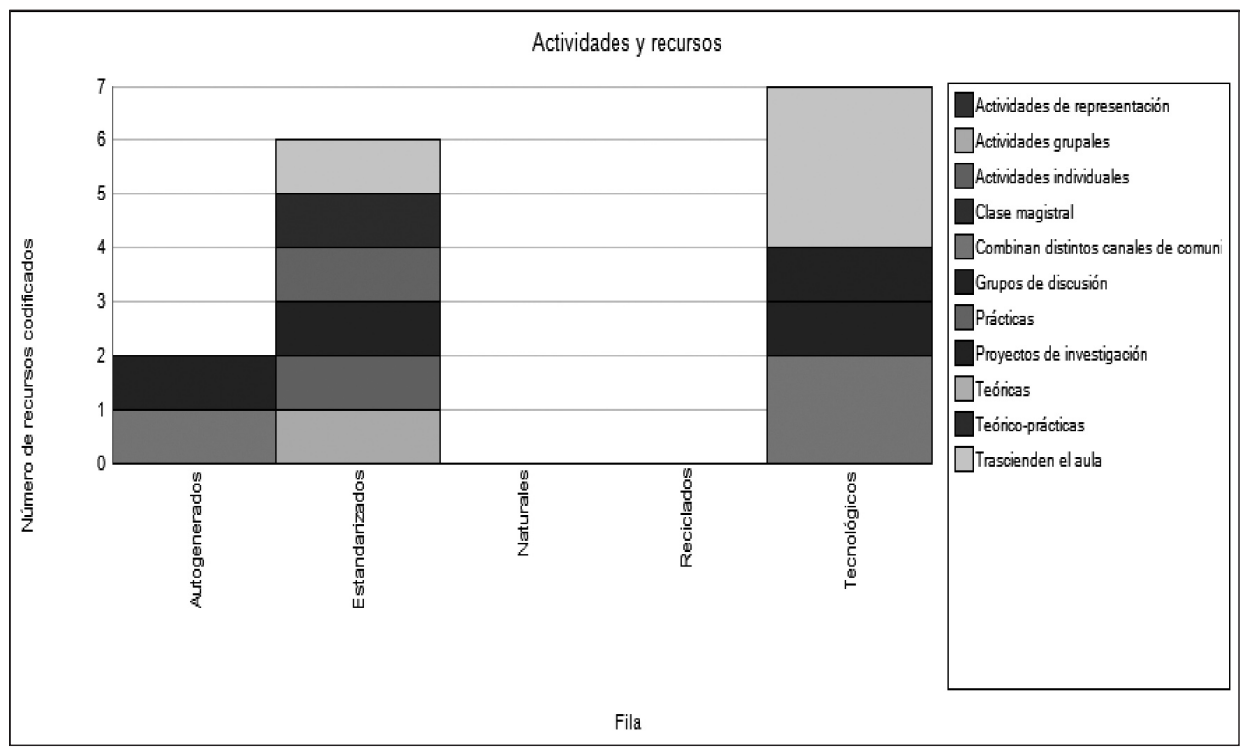

Si se analizan los recursos autogenerados se observa que éstos se generan y se emplean en proyectos de investigación y en actividades que combinan diferentes canales de comunicación.

Los recursos estandarizados, principalmente el texto de la Carta de la Tierra, es usado para la mayoría de las actividades, ya sean individuales, grupales, en grupos de discusión, en prácticas, en teórico-prácticas o fuera del aula.

Sin embargo, la mayoría de recursos tecnológicos propician que se realicen mayoritariamente actividades que trasciendan el aula, que combinen diversos canales de comunicación, y son más empleados en grupos de discusión y en proyectos de investigación.

Aclarar que en las experiencias no aparecen menciones explícitas de la relación entre las diversas actividades y los recursos naturales y los recursos reciclados.

\subsection{Compromisos}

Como compromisos asumidos para el futuro se han considerado: la ampliación de la experiencia a otros contextos y la continuación de la misma. 
TABLA 9. COMPROMISOS

\begin{tabular}{|c|c|c|c|}
\hline Categoría & Subcategoría & F1 & F2 \\
\hline \multirow{2}{*}{ Compromisos } & Ampliación a otros contextos & 2 & 2 \\
\cline { 2 - 4 } & Continuación de la experiencia & 7 & 12 \\
\hline
\end{tabular}

La tabla anterior muestra como la mayoría de los compromisos asumidos son continuando la experiencia a lo largo del tiempo. "La meta es trabajar para incluir estos ensayos en una lectura de composición utilizada en instituciones de los Estados Unidos" (Blaze y Wolhpart, 2008, 123).

Solamente en los casos de Yeveran (Armenia) y de Granada (España) se plantean ampliar a otros contextos cercanos sus experiencias. «[...] en el futuro se deben impartir una serie de talleres de entrenamiento para maestros a lo largo de todo el país" (Bakhnova, 2008, 136).

\section{GrÁFICO 10. COMPROMISOS Y LUGAR DE LA EXPERIENCIA}

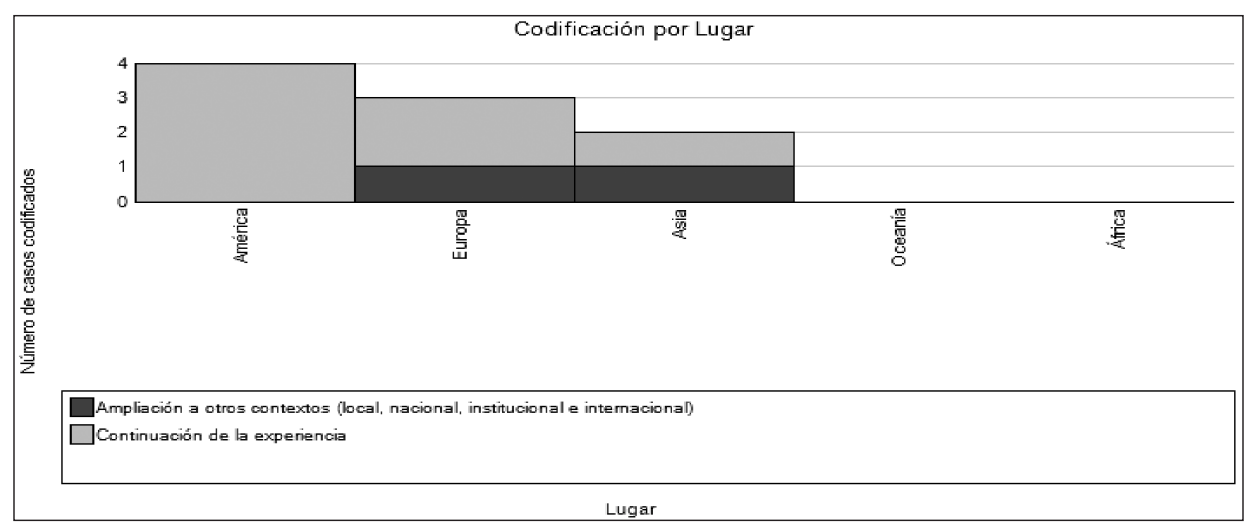

Las experiencias que tienen lugar en Oceanía y África no explicitan ningún compromiso para el futuro. Por el contrario, en Asia y Europa se comprometen de los dos modos, mientras que en América sólo desean seguir desarrollando la experiencia.

\section{CONCLUSIONES}

Analizando el conjunto de experiencias en la etapa de Educación Superior, inspiradas en principios los principios de la Carta de la Tierra y publicadas en su página web oficial, encontramos que: 
- La tendencia es que estas prácticas surjan de la motivación intrínseca de una institución o una persona. Son las intenciones de los docentes las que les incitan a realizar lo que hacen. Si los reformadores o agentes de cambio externos pasan por alto sus necesidades o las tratan como si fueran irrelevantes éstos se desalentarán y se sentirán frustrados, incluso puede generar resentimiento y resistencia (Fullan, 2002). Así pues, el cambio educativo va a ser eficaz si se genera desde una motivación mixta, que compatibilice los intereses y necesidades particulares con los externos.

- Con respecto a los participantes, en estas experiencias, son pocos los agentes externos al centro que se involucran desde el diseño de la misma. En el futuro, deberíamos seguir trabajando para hacer participes de las prácticas ecopedagógicas a aquellas personas que se sienten desligadas del Sistema Educativo. Además se debe procurar que la comunidad educativa se sienta parte responsable en el desarrollo conjunto de estas acciones innovadoras. Necesitamos cambiar nuestra forma de relacionarnos para implicar a más personas y para ello es necesario tener en cuenta la propuesta expresada por Moacir Gadott en el siguiente párrafo: "Comprender que somos interdependientes. La Tierra es una sola nación y nosotros, los habitantes de la Tierra, somos sus ciudadanos" (Gadotti, 2008, 24). Que se tienda a incluir la comunidad educativa y agentes externos en prácticas sustentables, promocionando una cultura colaborativa junto a facultades o escuelas de Educación Superior incrementa las probabilidades de éxito (Rodríguez, 2006).

- La ecopedagogía propone recuperar la afectividad. "Nosotros somos humanos, porque sentimos, no sólo porque pensamos" (Gadotti, 2008, 24). En los objetivos explicitados en las experiencias los objetivos afectivoemocionales son tan importantes o más en número de menciones que los objetivos cognitivos. En las experiencias analizadas se le concede importancia a la inteligencia emocional que autores como Goleman (1996), entre otros, reivindican. "Hay que profundizar en la educación [...], abrirla a las otras inteligencias, a las demás líneas de desarrollo" (Fernández y Carmona, 2009, 74). Aunque, como recogen los datos, son más importantes los objetivos actitudinales y los de procedimiento. Una nueva cultura medioambiental, basada en la ética, conlleva el aprendizaje de nuevos conocimientos, procedimientos, valores y actitudes. "De este modo, se hace difícil otra educación ambiental si no se atiende, junto a los conocimientos la dimensión afectiva, valorativa; si no está presente el componente moral que debe impregnar nuestras relaciones con la naturaleza" (Ortega y Romero, 2009, 171). Así pues, todavía podemos evolucionar en nuestras experiencias hasta equilibrar la importancia concedida a los diversos tipos de objetivos. "Si los seres humanos nos hemos dedicado hasta ahora a conocer el mundo y transformarlo, ha llegado la hora de que aprendamos a amarlo" (Saura y Hernández, 2008, 203). 
- Con respecto a los contenidos, estás prácticas tienden a ser holísticas en la medida en que ponen en práctica lo que Morin (1996) llama "pensamiento ecologizado", por el que se contemplan distintos contenidos relacionándolos entre sí. Éste es un aspecto innovador pues,

es una oportunidad para la educación para renovar los viejos sistemas basados en los principios y los valores competitivos y para introducir una cultura de la sostenibilidad y la paz en las comunidades escolares, con el fin de ser más cooperativos y menos competitivos. La sostenibilidad puede ser una categoría fundamental para la reconstrucción de los actuales sistemas educativos, que aún se basan en una visión depredadora del mundo. La educación ambiental y educación para el desarrollo sostenible son los ejes fundamentales de estas reformas cuando se asocian con los derechos humanos, derechos de género, los derechos democráticos, la paz y la sostenibilidad (Gadotti, 2010, 210).

La respuesta al problema ambiental no puede abordarse sólo considerando los problemas ambientales, pues sin unas relaciones justas y éticas entre los seres humanos es imposible establecer relaciones armónicas con la naturaleza (Bellver, 2000). En estas experiencias se relacionan aspectos ambientales, ecológicos, de derechos humanos, éticos, relacionados con la democracia, la justicia, la economía y, en menor medida, con la diversidad cultural. Este último tópico puede continuar trabajándose en próximas prácticas ecológicas, ya que cuenta con el menor número de menciones en las experiencias analizadas.

Que se relacionen los aspectos teniendo en cuenta que somos parte de la comunidad de la vida es un elemento innovador de estas experiencias porque, como defiende Morin (2005), la escuela ha inculcado en nosotros la creencia de que hay que fragmentar la realidad, nos enseña a pensarla separando las distintas dimensiones del complejo tejido de lo real, a aislar contenidos y disciplinas sin asociarlas. De algún modo, estamos dominados por un paradigma que nos limita, contrario a las visiones ecológicas que enfatizan las conexiones con los contextos, habituados a concebir a la persona de manera fragmentada y ésta, a su vez, separada de su entorno, olvidando que "la Naturaleza funciona como una red de relaciones intrínsecamente dinámicas, donde las propiedades de las partes que forman un sistema particular sólo pueden ser entendidas a partir de la dinámica de todo el conjunto" (Caride y Meira, 2001, 67).

- En las experiencias analizadas se han empleado metodologías activas que fomentan la participación, interdisciplinares, centradas en el alumnado y diversificadas. Metodologías acordes con el fin de educar en valores permiten dar voz a todos los participantes e implicarse en su proceso de aprendizaje. Estas metodologías de carácter activo, centradas en el alumnado, transversales..., parecen superar la difícil disociación entre lo que hacemos y lo que deberíamos hacer, dando un paso más, permitiendo 
plasmar las intenciones en hechos. En este sentido, converge con lo propuesto desde el Espacio de Educación Superior que:

ha intentado que el estudiante participe de forma activa mediante estrategias metodológicas que promuevan la iniciativa del alumno, la reflexión, la experimentación, el aprendizaje autónomo tutelado por el profesor. Se desea con ello fomentar y garantizar su compromiso individual, lograr que los alumnos sean protagonistas de su aprendizaje y lo construyan formándose criterios propios (Gargallo, 2009, 2).

Como la mayoría de experiencias se han realizado a escala micro, concretamente en el ámbito del centro. Sería interesante poder seguir analizando experiencias futuras que tengan un carácter internacional para conocer el tipo de metodologías que se pueden llevar a cabo en ese espacio concreto.

- $\quad$ En la etapa de Educación Superior son frecuentes las clases magistrales, sin embargo, en las experiencias analizadas no es así. Es el grupo de discusión el tipo de actividad más referenciado. Este hecho está en consonancia con lo que se promueve desde el Espacio Europeo de Educación Superior, donde se busca que el alumnado sea el protagonista de su aprendizaje. "Se te propondrán actividades para que participes activamente: trabajo en equipo, estudios de caso, trabajo para proyectos y aprendizaje basado en problemas, más allá del que habitualmente se hacía en muchas clases, que era escuchar y tomar apuntes" (Espacio Europeo de Educación Superior, 2011). Esto evidencia que el tipo de actividades promovidas en la Educación Superior está cambiando, que se está innovando, de modo que están en la línea de las metodologías activo-participativas. Por este motivo también se incluyen actividades poco comunes en los sistemas oficiales europeos como las representaciones (teatro, poesía, canciones, juegos de roles...). Además, las actividades promovidas en las experiencias analizadas logran trascender el aula e ir más allá, empleando espacios naturales y distintos canales de comunicación que se adapten a la diversidad de contextos y estilos de aprendizaje de los participantes. Como decíamos anteriormente, ésta es una manera de favorecer que los contenidos se interioricen de un modo más potente y propiciar el desarrollo de diferentes inteligencias.

Las actividades individuales cuentan con mayor número de menciones que las grupales, porque la mayoría de experiencias comienzan dando información que tienen que asimilar personalmente para luego llegar a realizar actividades grupales con unos conocimientos previos. En futuras investigaciones podríamos estudiar la dedicación temporal a los distintos agrupamientos, para conocer si les conceden más importancia a las tareas individuales o a las grupales. 
- Los recursos más empleados son los estandarizados porque, en prácticamente todas las experiencias, se emplea el documento de la Carta de la Tierra como punto de partida para crear grupos de discusión. Existe una clara tendencia también a usar recursos tecnológicos que son menos contaminantes, dan mayor difusión a las ideas y pueden combinar diferentes canales (fotos, vídeos, palabras, poesías...). Se observa, no obstante, un déficit en el uso de recursos naturales.

- Con respecto al diseño, desarrollo y evaluación de las experiencias se constata la importancia concedida a la colaboración en estos procesos, al reconocimiento y a los apoyos externos. Las relaciones democráticas y satisfactorias son la base de una cultura colaborativa que promueve la implicación, la disposición, el apoyo o ayuda mutua y el compromiso, aspectos fundamentales en la transformación de la práctica educativa (Pérez Gómez, 1998). Esta transformación se fortalece con apoyos externos, sobre todo de índole económica y con el reconocimiento social que reforzará la satisfacción y la motivación del grupo.

Por otro lado se observa que la evaluación ha pasado a un segundo plano, no siendo especificada en las mismas. En futuras experiencias sería útil conocer qué métodos usan para evaluarlas. Autores como Gimeno Sacristán y Pérez Gómez (1992) consideran que es importante evaluar las experiencias para conocer si los objetivos propuestos se han cumplido, para adecuar o mejorar nuestras prácticas, detectar los progresos del alumnado, pensar y planificar la práctica educativa, etc. La evaluación es clave en la innovación, es el referente desde el que actuar, por lo que no puede descuidarse.

- Los compromisos asumidos para el futuro aún son escasos, sobre todo cuando lo que se pretende es ampliar esa experiencia a otros contextos. Hay mucho por hacer y es importante continuar sensibilizando, implicando a los demás y visibilizando la necesidad de seguir siendo activos y emprender acciones que contribuyan a construir un futuro más sustentable.

En suma, la ecopedagogía implica una nueva visión del mundo, nuevas formas de relación entre sociedad-naturaleza que involucra a los individuos en transformaciones personales, sociales, institucionales y culturales. No es una unidad de aprendizaje suplementaria que se anexa a los diseños curriculares; demanda transversabilidad y la formación de educadores ambientales que puedan realizar esta integración, tanto en la teoría como en la praxis. Esto es, la ecopedagogía contribuye a mejorar la calidad de vida y del medio ambiente, a la protección y conservación de nuestro entorno, hacer hincapié en los problemas ambientales, proporcionar elementos para la participación y la toma de decisiones (Sterling, 2010). Estos aspectos innovadores han sido contemplados en las experiencias analizadas, inspiradas por la Carta de la Tierra, y han producido mejoras en nuestras vidas. Por lo que afirmamos que la Carta de la Tierra "se trata, sin duda, de un instrumento 
de sensibilización educativa pero, sobre todo, es una guía imprescindible para la educación moral de los ciudadanos en un modelo cuya urgencia es contribuir al desarrollo sostenible en todas sus dimensiones" (Murga-Menoyo, 2009, 257). La difusión de sus principios y la creación de una web en la que compartir «buenas prácticas", en la que poder difundir e intercambiar materiales diversos y en la que aunar esfuerzos de todo el mundo en pro del mismo fin, ha generado resultados innovadores porque no sólo se ha logrado concienciar a las personas, sino que también ha logrado que muchas de ellas cambien sus objetivos, hábitos e incluso sus recursos. Por ello, la Carta de la Tierra es un buen instrumento para sensibilizar a niños, jóvenes, adultos o mayores, innovar en la escuela, transformar el modo de comportarnos y relacionarnos en sociedad y con el planeta.

Por todo ello, conocer la Carta de la Tierra y las experiencias educativas innovadoras que desde ella se promueven es una forma de contribuir a reforzar el compromiso de las futuras generaciones con un estilo de vida sostenible.

\section{REFERENCIAS BIBLIOGRÁFICAS}

BAKnova, M. (2008) La Carta de la Tierra como herramienta pedagógica para la sustentabilidad en la Universidad Estatal de Armenia, en Vilela, M. (coord.) Experiencias educativas con la Carta de la Tierra. México, Semarnat, 131-136.

BARDín, L. (1986) El análisis de contenido. Madrid, Akal.

Bellver, V. (2000) Las ecofilosofías, en Ballesteros, J. y Pérez, J. (eds.) Sociedad y medio ambiente. Madrid, Trotta, 251-269.

Belousa, I. y Micule, I. (2008) La experiencia del Instituto de Educación Sustentable. Facultad de Educación y Administración, en VILELA, M. (coord.) Experiencias educativas con la Carta de la Tierra. México, Semarnat, 169-174.

Blaze, P. y Wohlpart, A. J. (2008) La Carta de la Tierra enfocada en el plan de estudios y la investigación: una universidad estadounidense, en VILELA, M. (coord.) Experiencias educativas con la Carta de la Tierra. México, Semarnat, 119-123.

Boff, L. (2006) Respeto y cuidado hacia la comunidad de la vida mediante el entendimiento, compasión y amor, en Blaze, P.; Vilela, M. y RoerinK, A. (eds.) La Carta de la Tierra en acción. Hacia un mundo sostenible. Amsterdam, Kit Publishers, 43-46.

CARBONELL, J. (2002) El profesorado y la innovación educativa, en CAÑAL DE LEÓN, P. (coord.) La innovación educativa. Madrid, Ediciones Akal, 11-26.

CARIDE, J. A. y MEIRA, P. A. (2001) Educación ambiental y desarrollo sostenible. Barcelona, Ariel,

CARTA DE la Tierra (2000) Consultado el 20 de septiembre de 2010. www.earthcharterinaction.org.

ESPACIO EUROPEO DE EDUCACIÓN SUPERIOR (2011) Estructura antigua-estructura nueva. Consultado el 1 de junio de 2011. http://www.eees.es/es/eees-estructura-antiguaestructura-nueva-eees.

Fernández, A. y Carmona, G. (2009) Re-hacer la educación: los mapas del desarrollo humano. Teoría de la Educación. Revista Interuniversitaria, 21 (2), 45-78.

- (2010) Trabajando la Carta de la Tierra: Una experiencia de aprendizaje vivencia. Revista de Ciencias de la Educación, 221, enero-marzo, 107-118. 
106 MARÍA ARENAS ORTIZ, EVA FRANCISCA HINOJOSA PAREJA Y MARÍA CARMEN LÓPEZ LÓPEZ

LA CARTA DE LA TIERRA: EXPERIENCIAS INTERNACIONALES DE INNOVACIÓN EN EDUCACIÓN SUPERIOR

FernándeZ, A. y Conde, J. L. (2008) Experimentando con la Carta de la Tierra: Actividades de la Facultad de Ciencias Educativas, en VILELA, M. (coord.) Experiencias educativas con la Carta de la Tierra. México, Semarnat, 107-112.

- (2010) La práctica de la ecopedagogía en la formación inicial de maestros. Investigación en la Escuela, 71, 39-50.

FERnÁNDEZ, A. y López, M. C. (2010) La educación en valores desde la carta de la tierra. Por una pedagogía del cuidado. Revista Iberoamericana de Educación, 53 (4), 1-19.

Fullan, M. (2002) Las fuerzas del cambio: Explorando las profundidades de la reforma educativa. Madrid, Akal.

GadotTi, M. (2008) What we need to learn to save the planet. Journal of Education for Sustainable Development, 2 (1), 21-30.

- (2010) Reorienting education practices towards sustainability. Journal of Education for Sustainable Development, 4 (2), 203-211.

Gargallo, A. (2009) Metodologías activas en la dirección estratégica de la empresa: implicación de los alumnos en el análisis estratégico de la universidad. Revista Iberoamericana de Educación, 48 (5), 1-8. Consultado el 1 de junio de 2011. http://www.rieoei.org/ expe/2487Gargallo.pdf.

Goleman, D. (1996) Inteligencia emocional. Barcelona, Kairós.

Gómez-Heras, J. M. G. (2000) Introducción: Dignidad de la naturaleza y ética medioambiental, en Gómez-Heras, J. M. G. (comp.) La dignidad de la naturaleza. Ensayos sobre ética y filosofía del medio ambiente. Granada, Comares, 1-20.

Gorvachev, M. (2006) El tercer pilar del desarrollo sostenible, en Blaze, P.; Vilela, M. y Roerink, A. (eds.) La Carta de la Tierra en acción. Hacia un mundo sostenible. Amsterdam, Kit Publishers, 9-10.

GutiérRez, J.; Benayas, J. y CAlvo, S. (2006) Educación para el desarrollo sostenible: evaluación de retos y oportunidades del decenio 2005-2014. Revista Iberoamericana de Educación, 40, 25-69.

Jefe Seattle (1855) Carta del Jefe Seattle. Consultado el 15 de marzo de 2011. http://www. ciudadseva.com/textos/otros/seattle.htm.

Jiménez, A.; Cedeño, E.; Salas, F.; San lee, F.; Peña, G.; Vega, H.; Sánchez, N. y Zamora, R. (2008) Un acercamiento integral hacia la sustentabilidad: experiencias de la Universidad Nacional de Costa Rica y el Centro para Estudios Generales, en VILELA, M. (coord.) Experiencias educativas con la Carta de la Tierra. México, Semarnat, 113-118.

Jiménez, F. y López, M. (2007) Hablemos de Paz. Pamplona, Editorial Java.

JiméNEZ, A. y MARTín, M. (2008) Integración de la educación para la sustentabilidad en la formación de maestros, en Vilela, M. (coord.) Experiencias educativas con la Carta de la Tierra. México, Semarnat, 125-130.

Legardera, F. (2008) Proyecto Carta de la Tierra... en acción motril, en Vilela, M. (coord.) Experiencias educativas con la Carta de la Tierra. México, Semarnat, 153-157.

Link, T. (s/f) Un Curso Universitario Basado en la Carta de la Tierra. Universidad Estatal de Michigan, EE. UU. Consultado el 31 de diciembre de 2012. http://www.earthcharterinaction.org/invent/images/ uploads /4Univ\%20Estatal\%20Michigan\%20-\%20EUA.pdf.

Morin, E. (1996) El pensamiento ecologizado. Consultado el 26 de abril de 2011. http:// www.ugr.es/ pwlac/G12_01Edgar_Morin.html.

- (1999) Los siete saberes necesarios para la educación del futuro. París, UNESCO.

- (2005) Introducción al pensamiento complejo. Barcelona, Gedisa. 
Murga-Menoyo, M. A. (2009) La Carta de la Tierra: Un referente de la Década por la Educación para el Desarrollo Sostenible. Revista de Educación, número extraordinario, 239-262.

NARANjo, C. (2004) Cambiar la educación para cambiar el mundo. Gasteiz, Vitoria, La Llave D. H.

Noguera, A. P. (2004) El reencantamiento del mundo. Colombia, Universidad Nacional de Colombia-Programa de la Naciones Unidas para el Medio Ambiente.

Novo, M. (2009) La educación ambiental: una genuina educación para el desarrollo sostenible. Revista de Educación, número extraordinario, 195-217.

OlvitT, L.; SisitKa, H. y Schudel, I. (2008) La Carta de la Tierra como punto de análisis y discusión: reflexiones sobre cursos de educación ambiental, en VILELA, M. (coord.) Experiencias educativas con la Carta de la Tierra. México, Semarnat, 147-151.

Ortega, P. y Romero, E. (2009) La dimensión ética de la crisis medioambiental. Propuestas pedagógicas. Teoría de la Educación. Revista Interuniversitaria, 21, 1, 161-178.

PÉREZ, A. (1998) La cultura escolar en la sociedad neoliberal. Madrid, Morata.

Pérez, A. y Gimeno, J. (1992) Comprender y transformar la enseñanza. Madrid, Morata.

Robson, A. (2008) Convirtiéndose en un campus sustentable: la experiencia en los encuentros con comunidades de la Carta de la Tierra, en VILELA, M. (coord.) Experiencias educativas con la Carta de la Tierra. México, Semarnat, 141-146.

Rodríguez, D. (2006) Modelos para la creación y gestión del conocimiento: Una aproximación teórica. Educar, 37, 25-39.

SAURA, P. y Hernández, M. A. (2008) La evolución del concepto de sostenibilidad y su incidencia en la educación ambiental. Teoría de la Educación. Revista Interuniversitaria, 20, 179-204.

SterLING, S. (2010) Living in the Earth: Towards an Education for Our Tim. Journal of Education for Sustainable Development, 4 (2), 213-218.

TARASOVA, N. P. y ZAITSEv, V. A. (2008) Educación sustentable en Rusia: la experiencia de la Universidad Mendeleyev de Tecnología Química, en Vilela, M. (coord.) Experiencias educativas con la Carta de la Tierra. México, Semarnat, 163-168.

TAYlor, P. y Bosselmann, K. (2008) La Carta de la Tierra en el salón de clases: transformando el papel de la ley, en Vilela, M. (coord.) Experiencias educativas con la Carta de la Tierra. México, Semarnat, 159-162.

Vilela, M. (coord.) (2008) Experiencias educativas con la Carta de la Tierra. México, Semarnat. ZingaretTi, H. (2001) Esperanza y pedagogía. Mendoza, Ediunc. 